
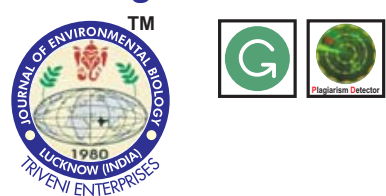

\title{
Physiological properties of Engraulis japonicus muscle protein hydrolysates prepared by subcritical water hydrolysis
}

ISSN: 0254-8704 (Print)

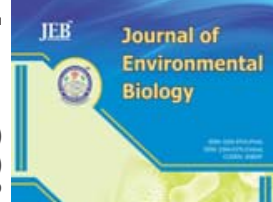

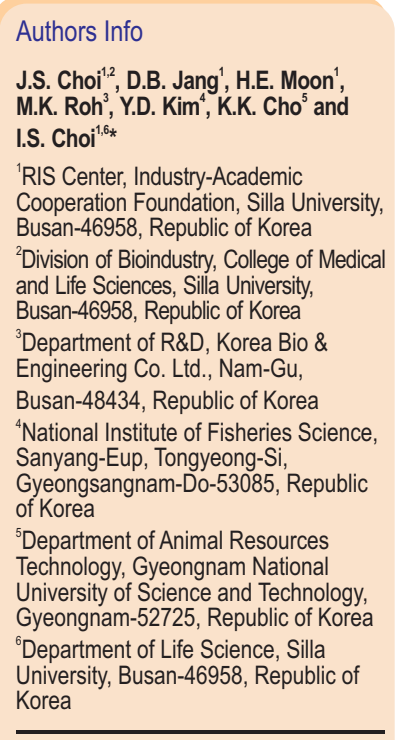

${ }^{*}$ Corresponding Author Email : ischoi@silla.ac.kr

Key words

Antioxidant activity,

Engraulis japonicus

Hydrolysate,

Subcritical water hydrolysis,

Tyrosinase inhibitory activity

\section{Publication Info}

Paper received: 14.03 .2015

Revised received: 14.07.2016

Accepted: 12.09.2016

\section{Abstract}

Aim: To evaluate the beneficial biological activities of Engraulis japonicus muscle protein, the antioxidant and tyrosinase inhibitory activities of $E$. japonicus muscle protein hydrolysates prepared by subcritical water hydrolysis were investigated.

Methodology: To evaluate the bioactivity of $E$. japonicus subcritical hydrolysates, the applied temperature (pressure) was $140^{\circ} \mathrm{C}$ (2.6 bar); the reaction times were $0,5,10,15$ and $20 \mathrm{~min}$.

Results: After 10 min of subcritical hydrolysis of particles obtained using $80-200$ mesh, $46.39 \%$ of the E.japonicus muscle protein was hydrolyzed at $140^{\circ} \mathrm{C}$. According to the response surface methodology results, particles generated with 80-200 mesh E. japonicus powder exhibited an increased yield of hydrolysates. The highest DPPH-radical-scavenging activity (34.91\%) occurred in 60-80-mesh sized protein hydrolysates treated at $140^{\circ} \mathrm{C}$ for $15 \mathrm{~min}$, and the highest tyrosinase inhibitory activity (99.24\%) was identified in $80-200$-mesh sized protein hydrolysates treated at $140^{\circ} \mathrm{C}$ for $5 \mathrm{~min}$. Changes in the molecular weight distribution of $E$. japonicus muscle proteins after subcritical water hydrolysis were assessed by sodium dodecyl sulfate-polyacrylamide gel electrophoresis.

Interpretation: Subcritical water hydrolysis is a suitable technique for generating $E$. japonicus muscle protein hydrolysates with useful biological activities, within a short (5-15 min) time frame.

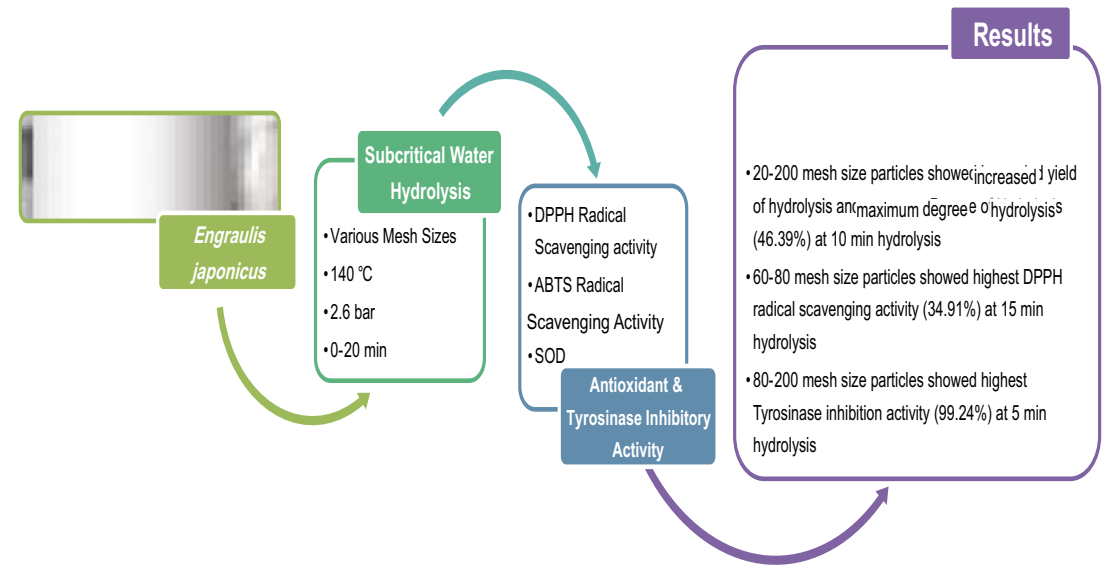

Subcritical water hydrolysis is a suitable technique for generating $E$. japonicusmuscle protein hydrolysates within a short time $(5-15 \mathrm{~min})$ time frame. 


\section{Introduction}

Engraulis japonicus is a small, pelagic schooling fish that feeds on plankton, and is widely distributed off the Pacific Ocean south of the Sea of Okhotsk. It is commonly found on the coast of the Korean peninsula, including Japan and China. This species is an important commercial fishing resource, and is the main source of boiled-dried products and fermented fish sauce in Korea (Oh et al., 2009) due to its high protein and calcium content and attractive taste (Heu and Kim, 2002). The annual catch of anchovies in Korea ranges from $150 \times 10^{3}-250 \times 10^{3}$ tons (Ministry of Oceans and Fisheries, 2013), and are mainly processed into boiled-dried products and fermented fish sauce. However, when large quantities are harvested, the fish are also processed into frozen products or fishmeal (Oh et al., 1989). To improve the value of anchovy products, attempts have been made to develop new bio-functional material (Ji et al., 2002; Choi et al., 2003).

Biologically active peptides from dietary proteins have numerous physiological functions, including antioxidant, antimicrobial, anticancer, antihypertensive, immunomodulatory, and antithrombotic effects (Udenigwe and Aluko, 2012; Hartmann and Meisel, 2007). Previous studies have shown that various peptides or hydrolysates derived from fish or seafood muscle proteins and wastes exhibit beneficial effects on health benefits superior to the crude materials (Pádraigín and Richard, 2012; Hordur and Barbara, 2000). Antioxidant and angiotensinconverting enzyme inhibitory activities have been reported for a peptide generated from decomposition of anchovy muscle by autolysis or protease addition (Park et al., 2005; Choi et al., 2003; Ji et al., 2002).

Various methods have been utilized to induce hydrolysis of fish muscle and waste, including chemical (acid, alkali, or catalytic) hydrolysis (Gao et al., 2002), enzymatic hydrolysis (Ji et al., 2002; Hsu et al., 2009), and gamma irradiation hydrolysis (Choi et al., 2011). Chemical hydrolysis requires strong reaction conditions and often results in environmental pollution. Enzymatic hydrolysis is difficult to control with respect to $\mathrm{pH}$, time, and the ratio of enzyme and substrate; is expensive; and requires a prolonged production cycle (Choi et al., 2016; Uddin et al., 2010). Finally, gamma irradiation hydrolysis demands large-scale facilities and is costly.

Recently, a new technology known as subcritical water technology, has been introduced that has been adapted for hydrothermal liquefaction and involves a reaction of biomass and water at elevated temperatures and pressures. This technique has been utilized for various biomasses, including proteins, carbohydrates and fatty acids (Toor et al., 2011). When water is heated under pressure its dielectric constant and density change, which results in a change in its solvent and reactant properties (Kruse and Dinjus, 2007). Under these conditions, biomass is decomposed to form new products. The advantages of using subcritical hydrolysis, a relatively simple process, include a short hydrolysis time, no requirement for addition of catalysts and the ability to simultaneously sterilize the product. Additionally, hydrolysis in subcritical water is regarded as an environment friendly technology (Choi et al., 2016; Uddin et al., 2010).

Despite several advantages of subcritical hydrolysis, no attempt to utilize this technique on muscle from $E$. japonicus has been reported. Under subcritical water conditions, proteins undergo rapid hydrolysis to form peptides of various sizes and amino acids, which are further degraded to ammonia, organic acids, carboxylic acid and other products depending on the reaction conditions, including the original source, particle size, temperature, pressure and hydrolysis time (Toor et al., 2011).

In view of the above, the objective of the present study was to determine the optimal condition such as particle size, temperature, pressure and hydrolysis time for subcritical hydrolysis of $E$.japonicus muscle to produce useful peptides with biological properties, including antioxidant and tyrosinase inhibitory activities.

\section{Materials and Methods}

Materials: Boiled-dried E. japonicus (Engraulidae; Pacific anchovy or Japanese anchovy) (ca. 6-7 cm) captured from the South Sea of Korea was purchased from a local market in Busan, Korea. The fish were ground for 5 min using a grinder (Hanil, Seoul, Korea) after removing the head, tail fin and bone and the inner part. The ground fish powder was sieved and separated into $<40-$, 40-60-, 60-80-, and 80-200-mesh sized particles. For comparison, ground fish powder (not sieved) was also used as a control. Oil compounds were extracted from each ground fish powder using a three fold volume of ethyl acetate. This extraction procedure was repeated three times. The sieved and de-oiled fish powder samples were stored at $-20^{\circ} \mathrm{C}$ until further use.

Hydrolysis of deoiled $E$. japonicus powder in subcritical water: Subcritical water hydrolysis was performed following the method of Choi et al. (2016). Briefly, a 4-g sample and $400 \mathrm{ml}$ of distilled water were charged in the reactor in 1:100 ratio (w/v). To evaluate the bioactivity of $E$. japonicus subcritical hydrolysates, the applied temperature (pressure) was $140^{\circ} \mathrm{C}$ (2.6 bar); the reaction times were $0,5,10,15$ and $20 \mathrm{~min}$.

Estimation of degree of hydrolysis: The degree of hydrolysis of hydrolyzed protein was determined as the ratio of the amount of a-amino acids released during hydrolysis to the maximum amount of a-amino acids in the ground and sieved $E$. japonicus powder, following the method of Benjakul and Morrissey (1997) with slight modification (Choi et al., in press). The absorbance of samples was measured at $420 \mathrm{~nm}$ to determine the $\alpha$-amino acid content, and a-amino acids were expressed in terms of L-leucine. Degree of hydrolysis was calculated as follows: $\mathrm{DH}(\%)=[(\mathrm{Lt}-$ $\left.L 0) /\left(L_{\max }-L 0\right)\right] \times 100$, where $L t$ is the amount of a-amino acids 
released at time $t ; \mathrm{L} 0$ is the amount of $a$-amino acids in the ground and sieved $E$. japonicus powder; $\mathrm{L}_{\max }$ is the maximum amount of $\mathrm{a}$ amino acids in the ground and sieved $E$. japonicus powder (Beak etal., 1995; Choi etal., 2016).

Response surface methodology (RSM): A regression analysis by central composite design was performed using RSM to determine the optimal conditions for subcritical water hydrolysis of $E$. japonicus powder. Minitab statistical software, version 16 (Minitab Inc., State College, PA, USA) was used to generate the design of the experiments, perform statistical analysis and create regression model. The variables in the study included two numerical factors, powder size $\left(X_{1}\right)$ and hydrolysis time $\left(X_{2}\right)$. Subcritical water hydrolysis of $E$. japonicus powder of different particle sizes was performed at $140^{\circ} \mathrm{C}$ for $0,5,10,15$ and $20 \mathrm{~min}$.

Color determination: The color of the samples was measured using a color-difference meter (CM-700d spectrophotometer; Konica Minolta Sensing, Inc., Tokyo, Japan) with a 1-cm-diameter cuvette. Color was expressed using $L$ (lightness) a (redness), and $b$ (yellowness) Hunter system values, which were monitored by a computerized system using Spectra Magic version 2.11 software (Minolta Cyberchrom, Inc., Osaka, Japan). The overall color difference $(\Delta E)$ was calculated by the following equation $\Delta E=$ $\left[(\Delta L)^{2}+(\Delta a)^{2}+(\Delta b)^{2}\right]^{1 / 2}$

1,1-Diphenyl-2-picrylhydrazyl (DPPH)-radical-scavenging effect: DPPH-radical-scavenging capacity of $E$. japonicus hydrolysate (50 $\mathrm{\mu g} \mathrm{d}$. wt.) was determined by the method of Blois (1958) and was calculated by the formula: new line Scavenging ability $(\%)=[1$ - (sample absorbance - sample color absorbance)/ control absorbance] × 100. L-ascorbic acid (Sigma, A5960) was used as positive control.

2,2'-Azino-bis-3-ethylbenzothiazoline-6-sulfonic acid (ABTS)-radical-scavenging effect: ABTS-radical-scavenging activity of $E$. japonicus hydrolysate ( $30 \mu \mathrm{g} \mathrm{d}$. wt.) was determined according to the method of Re et al. (1999) with some modifications. The antioxidant activity of the samples was calculated as: Scavenging ability $(\%)=[(\mathrm{Ac}-\mathrm{At}) / \mathrm{Ac}] \times 100$

where, At and Ac are the absorbance with and without samples, respectively. L-ascorbic acid was used as positive control.

Measurement of superoxide dismutase (SOD)-like activity: SOD-like activity of $E$. japonicus hydrolysate (10 $\mu \mathrm{g} \mathrm{d}$.wt.) was assayed following the method of Marklund and Marklund (1975) and calculated by the following equation:

$$
\text { SOD-like activity }(\%)=[(A-B) / A] \times 100
$$

where $A$ is the increase in the absorbance of control and $B$ is the increase in the absorbance of sample. L-ascorbic acid was used as positive control.

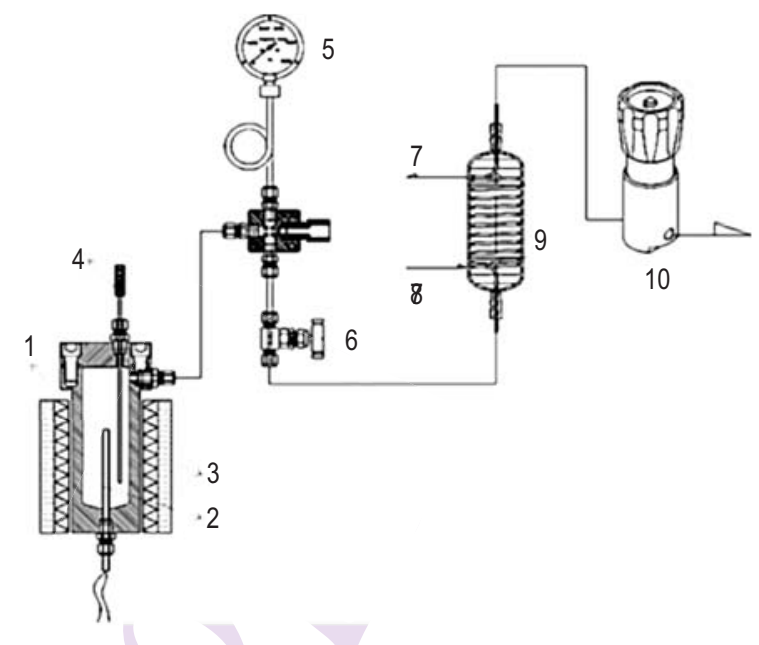

Fig. 1 : Schematic diagram of the laboratory-scale subcritical water reaction apparatus used in this study, adapted from Choi et al. (2016). (1) Reactor, (2) cartridge heater, (3) water jacket, (4) temperature indicator, (5) pressure gauge, (6) ball valve, (7) cool water out-flow, (8) cool water in-flow, (9) heat exchanger, and (10) back pressure regulator

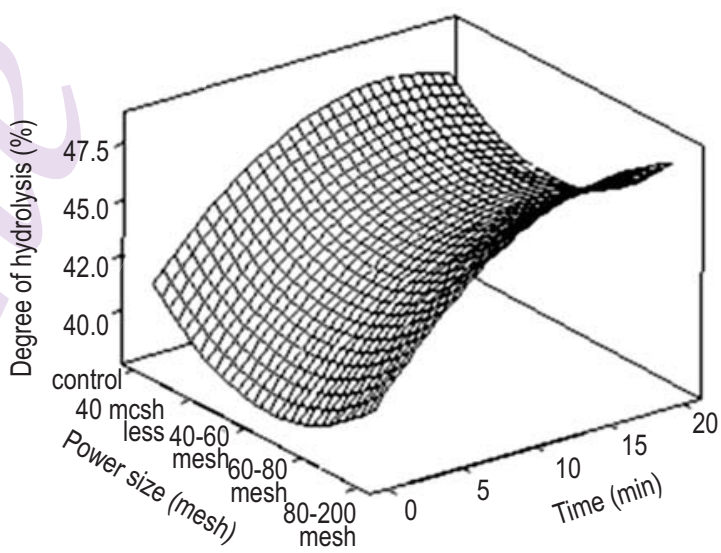

Fig. 2 : Response surface plot representing the effect of temperature and hydrolysis time on the yield of <40-, 40-60-, 60-80- and 80-200-mesh sized particles of Engraulis japonicus muscle protein subjected to subcritical water hydrolysis. The subcritical water hydrolysis was performed for $0,5,10,15$ and $20 \mathrm{~min}$ at $140^{\circ} \mathrm{C}$. Control means the ground and not sieved fish powder

Tyrosinase inhibitory activity: Tyrosinase activity of $E$. japonicus hydrolysate (40 $\mu \mathrm{g}$ d.wt.) was assayed by employing the method of Choi et al. (2003). The inhibitory effect of the sample on tyrosinase activity was calculated by the equation:

tyrosinase inhibitory activity $(\%)=[1-($ sample absorbance/ control absorbance) $] \times 100$ 
where, control refers to the absorbance of distilled water instead of the sample. L-ascorbic acid was used as positive control (Iwai etal., 2004).

Sodium dodecyl sulfate-polyacrylamide gel electrophoresis (SDS-PAGE): The reagent and electrophoresis kits were purchased from Bio-Rad Laboratories, Inc. (Hercules, CA, USA). The amount of protein loaded was adjusted to $20 \mu \mathrm{g}$ protein per lane. Electrophoresis was performed using precast 4-20\% MiniPROTEAN® TGX $X^{\mathrm{TM}}$ bis-Tris gels and a Mini-PROTEAN Tetra cell (cat. \#1658004) at $100 \mathrm{~V}$ in a Tris/glycine/SDS running buffer system (cat. \#161-0732) according to the manufacturer's instructions.Standard molecular weight markers (protein standard; cat.\#161-0374) were loaded in the first lane.

Statistical analysis: The experiments were performed independently at least three times. Analysis of variance (ANOVA) was used to determine significant differences $(P<0.05)$ among fish powder with different particle size $(<40-, 40-60-, 60-80$-, and 80-200-mesh sized particles) by each analytical characteristic and the ground fish powder (not sieved). The differences among samples were determined with Duncan's multiple-range test and considered statistically significant at $P<0.05$ level. The significance of the results was calculated using analysis of variance with SPSS version 10 software (SPSS, Inc., Chicago, IL, USA).

\section{Results and Discussion}

At $140{ }^{\circ} \mathrm{C}$, hydrolysis of homogenized (not sieved) $\mathrm{E}$. japonicus muscle powder with subcritical water proceeded at a high rate during the initial $5 \mathrm{~min}$ and thereafter, the proteins continued to undergo slight cleavage (Fig. 3A). A similar pattern was observed using <40-mesh sized particles of $E$. japonicus muscle powder. However, when 40-60- and 60-80-mesh sized particles of $E$. japonicus muscle powder were utilized, the hydrolysis degree (\%) increased proportionally with increasing hydrolysis time (min). On using E. japonicus muscle powder of 80200-mesh sized particles, subcritical water hydrolysis proceeded at a high rate during the initial $10 \mathrm{~min}$; thereafter, the proteins underwent further cleavage. This was likely due to the decomposition of amino acids, which facilitated excess hydrolysis rate at high temperature and pressure (Zhu et al., 2008; Toor et al., 2011; Choi et al., 2016). The degree of hydrolysis in 60-80and 80-200-mesh sized particles was highest at 20 and $10 \mathrm{~min}$ (46.28\% and $46.39 \%$ ), respectively at $140{ }^{\circ} \mathrm{C}$. The $\mathrm{a}$-amino acid content of $E$. japonicus muscle powder treated by acid hydrolysis was $604.38 \mu^{-1} g^{-1}$.

The predicted RSM model using a quadratic equation with factors for temperature $\left(X_{1}\right)$ and hydrolysis time $\left(X_{2}\right)$ is as follows: $Y=44.0167+0.1067 X_{1}+1.6017 X_{2}+0.0950 X_{1} X_{2}+$ $0.7106 X_{11}-0.6406 X_{22}$. According to the RSM results, as the size of muscle protein particle approached 40-60 mesh, the yield of hydrolysates decreased. However, using 80-200-mesh-derived particles E. japonicus powder, the yield of hydrolysates increased. E. japonicus muscle powder of several particle sizes exhibited longer reaction times and the yield increased for approximately $15 \mathrm{~min}$, followed by a subsequent decrease.

In E. japonicus muscle powder not subjected to subcritical water hydrolysis, the DPPH radical-scavenging activity was $16.16 \%$. Among the samples subjected to subcritical water hydrolysis, the 60-80-mesh sized protein hydrolysates treated at $140^{\circ} \mathrm{C}$ for $15 \mathrm{~min}$ exhibited highest DPPH-radicalscavenging activity, of $34.91 \%$. (Fig. 3B). The second-highest value $(27.99 \%)$ was in the $80-200$-mesh sized sample subjected to subcritical water hydrolysis for $15 \mathrm{~min}$. Including samples with different particle sizes and different hydrolysate times, the overall average activity was $<30 \%$. The DPPH-radical-scavenging activity of $2.5 \mathrm{\mu g} \mathrm{ml}^{-1} \mathrm{~L}$-ascorbic acid was $88.38 \pm 0.70 \%$.

ABTS-radical-scavenging activity was $12.67 \%$ in the sample not subjected to subcritical water hydrolysis. The $<40-$ mesh sized sample subjected to subcritical water hydrolysis at $140^{\circ} \mathrm{C}$ for $5 \mathrm{~min}$ showed highest ABTS-radical-scavenging activity of $55.39 \%$. The second-highest value $(42.07 \%)$ was detected in the 60-80-mesh sized sample subjected to subcritical water hydrolysis for $15 \mathrm{~min}$ including samples with different particle sizes and different hydrolysate times, the over all average ABTS radical-scavenging activity was $\leq 30.0 \%$ (Fig. $3 C$ ). The ABTS-radical-scavenging activity of $2.5 \mu \mathrm{g} \mathrm{ml}^{-1}$ L-ascorbic acid was $51.47 \pm 4.63 \%$.

In E. japonicus muscle not subjected to subcritical water hydrolysis, the SOD like activity was $20.06 \%$. Among the samples subjected to subcritical water hydrolysis, the 60-80-mesh sized sample treated at $140{ }^{\circ} \mathrm{C}$ for 15 min exhibited highest SOD like activity $(71.65 \%)$. The second-highest value $(67.19 \%)$ was observed in 80-200-mesh sized sample subjected to subcritical water hydrolysis for $5 \mathrm{~min}$. Including samples with different particle sizes and different hydrolysate times, the overall average SOD like activity was $\leq 42.0 \%$ (Fig. 3D). The SOD-like activity of $12.5 \mathrm{mg} \mathrm{ml}^{-1} \mathrm{~L}$-ascorbic acid was $34.83 \pm 0.64 \%$.

E. japonicus muscle not subjected to subcritical water hydrolysis inhibited tyrosinase activityby $14.65 \%$. The $80-200-$ mesh sized sample subjected to subcritical water hydrolysis at $140^{\circ} \mathrm{C}$ for 5 min exhibited highest inhibition of tyrosinase activity, at $99.24 \%$. The sample treated at $140^{\circ} \mathrm{C}$ for 0 min inhibited $54.57 \%$ of tyrosine activity. Including samples with different particle sizes and different hydrolysate times, the overall average tyrosinase inhibition was $\leq 41.64 \%$ (Fig. 3E). The tyrosinase inhibitory activity of $25 \mathrm{\mu g} \mathrm{ml}^{-1} \mathrm{~L}$-ascorbic acid was $52.72 \pm 2.45 \%$.

SDS-PAGE was used to examine the molecular weight distribution of proteins from the 60-80-mesh sized particles of $E$. japonicus muscle subjected to subcritical water hydrolysis at 140 

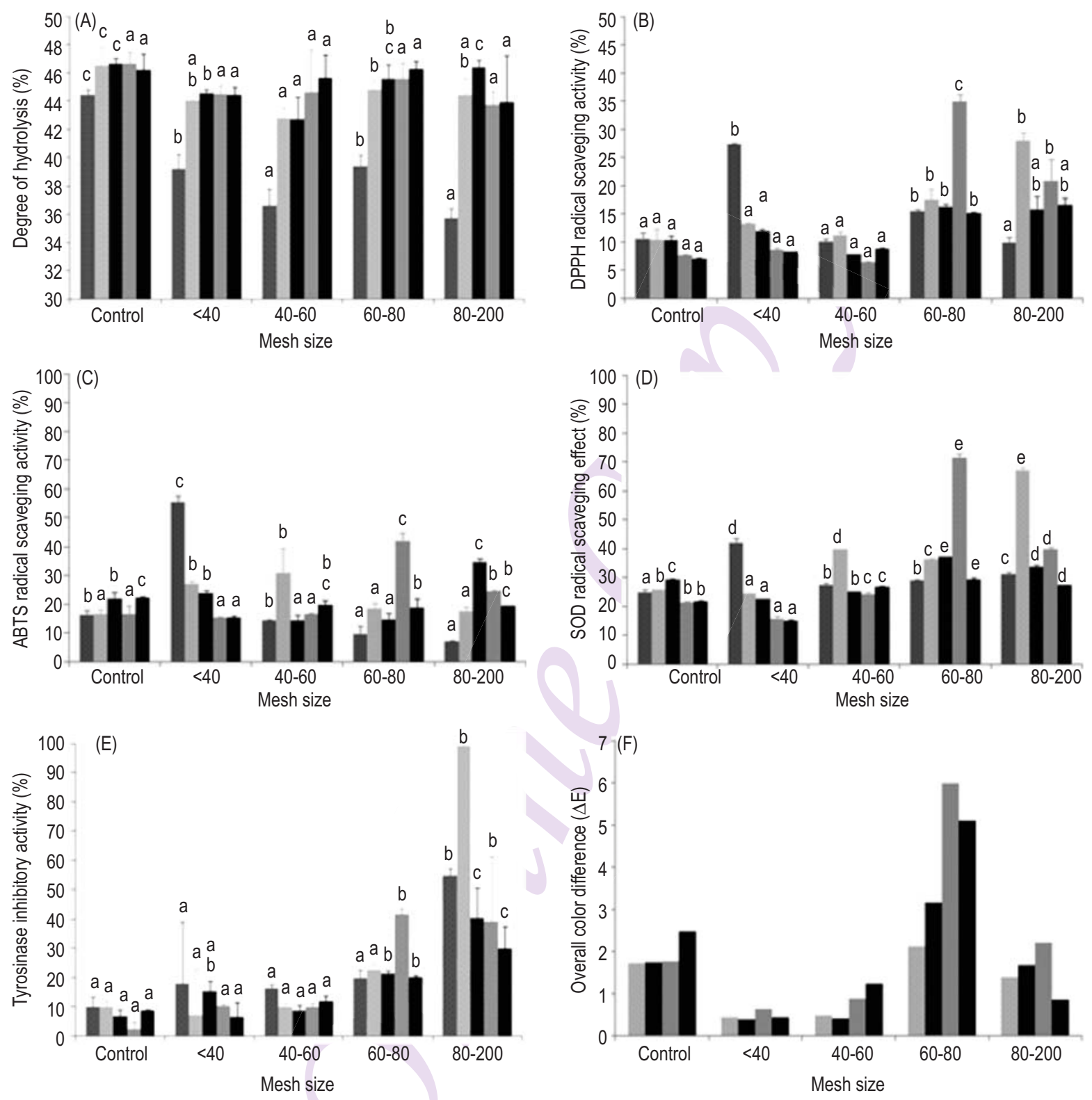

Fig. 3 : (A) Degree of hydrolysis (DH), (B) DPPH-radical scavenging activity, (C)ABTS-radical scavenging activity, (D) superoxide dismutase (SOD)-like activity, (E) Tyrosinase inhibitory activity, and (F) overall color difference $(\Delta E)$ of control (not sieved), <40-, 40-60-, 60-80-, and 80-200-mesh sized Engraulis japonicus hydrolysates following subcritical water hydrolysis for $0 \min (\square), 5 \min (\square), 10 \min (\square), 15 \min (\square)$ and $20 \min (\square)$ at $140^{\circ} \mathrm{C}$. Control means the ground and not sieved fish powder. $\Delta E$ : Overall color difference, $\left[(\Delta L)^{2}+(\Delta a)^{2}+(\Delta b)^{2}\right]^{1 / 2}$. All measurements were performed in triplicate, and values are means of three replicates. ${ }^{a-d}$ Means with different superscripts in the same column are significantly different at $P<0.05$ by Duncan's multiple range test

${ }^{\circ} \mathrm{C}$ for 0, 5, 10, 15 and 20 min. Hydrolyzed E. japonicus muscle consisted of proteins with diverse molecular weights. The major proteins had molecular weights of $79,44,32,22,18$, and $14 \mathrm{kDa}$ with $32-\mathrm{kD}$ a protein being the most abundant. All of these proteins appeared to be degraded by subcritical water hydrolysis (Fig. 4). Protein degradation was dependent on hydrolysis time, such that high-molecular-weight proteins were degraded to a greater degree with increasing hydrolysis times. The protein bands 
(kD)

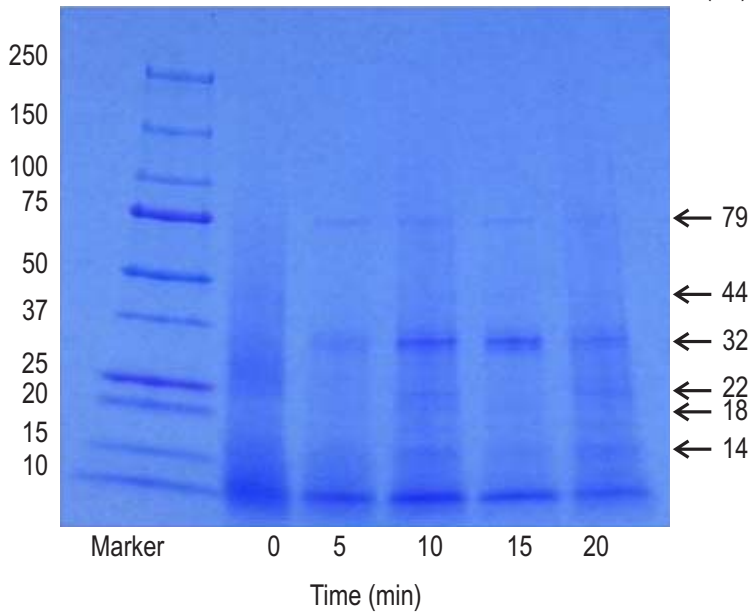

Fig. 4 : The effect of subcritical water hydrolysis on the molecular weight of 60-80-mesh-derived particles of Engraulis japonicus muscle protein. Molecular weights were investigated by sodium dodecyl sulfatepolyacrylamide gel electrophoresis (SDS-PAGE) at 0, 5, 10, 15 and 20 min after subcritical water hydrolysis at $140^{\circ} \mathrm{C}$. The left side indicates the molecular weight $(\mathrm{kDa})$ of the standard markers. Arrows indicate highmolecular-weight proteins that were changed by subcritical water hydrolysis

tended to disappear at a hydrolysis time longer than $15 \mathrm{~min}$, probably due to protein decomposition as a result of excess hydrolysis.

Subcritical water hydrolysis technique has been adapted for various biomasses, including proteins, carbohydrates and fatty acids, and the yield and form of hydrolysate differ depending on the reaction conditions, including the original source, particle size, temperature, pressure, hydrolysis time, etc. (Rogalinski et al., 2008; Toor et al., 2011). While it has been reported that the hydrolysate yield and form change can be affected by temperature, pressure, and hydrolysis time, few studies have reported that the hydrolysate yield can be altered by use of different particle sizes.

E. japonicus muscle has an excellent amino acid composition and is a unique source of nutrients and protein. As a result, $E$. japonicus muscle is one of the most important fishing resources, and is regarded as an economically important fish in Korea. Additionally, E. japonicus is utilized as a source of omega3 polyunsaturated fatty acids (Simopoulos, 1991), and the boiled $E$. japonicus residue can be used a valuable protein source. In fact, peptic $E$. japonicus hydrolysates exhibit various health benefits, including antioxidant activity (Choi et al., 2003; Park et al., 2005) and angiotensin-converting enzyme inhibitory activity (Ji et al., 2002; Park et al., 2005). However, these peptic E. japonicus hydrolysates were obtained from anchovy sauces or cooking discards. To the best of our knowledge, E. japonicus muscle protein hydrolysates prepared using subcritical water hydrolysis have not been investigated previously.

In the present study, the subcritical water hydrolysis technique showed potential for the preparation of $E$. japonicus muscle proteins with health-beneficial biological activities, including antioxidant and tyrosinase inhibitory activities. These results suggest that subcritical water hydrolysis, which has advantages of simplicity and rapidity and requires no catalysts or large-scale facilities, can be applied to the other areas of food industry.

\section{Acknowledgments}

This work was supported by the Global Healthcare Industry RIS Center, Ministry of Knowledge Economy, Republic of Korea. YDK was also supported by National Institute of Fisheries Science in Korea (R2016012).

\section{References}

Beak, H.H. and K.R. Cadwallader: Enzymatic hydrolysis of crayfish processing by-products. J. Food Sci., 60, 929-935 (1995).

Benjakul, S. and K.R. Morrissey: Protein hydrolysaes from Pacific whiting solid wastes. J. Agric. Food Chem., 45, 3423-3430 (1997).

Blois, M.S.: Antioxidant determination by the use of a stable free radical. Nature,181,1198-1200 (1958).

Choi, G.P., J.G. Seo and S.M. Kim: Antioxidative activity of low molecular weight biocompounds purified from anchovy (Engraulis japonicus) sauce. J. Kor. Fish. Soc., 36,321-326 (2003).

Choi, J.I., J.H. Kim and J.W. Lee: Physiological properties of tuna cooking drip hydrolysate prepared with gamma irradiation. Process Biochem., 46, 1875-1878 (2011).

Choi, J.S., H.E. Moon, M.K. Roh, Y.M. Ha, B.B. Lee, K.K. Cho and I.S. Choi: Physiological properties of Scomber japonicas meat hydrolysate prepared by subcritical water hydrolysis. J. Environ. Biol., 37, 57-63 (2016).

Gao, M.T., M. Hirata, E. Toorisaka and T. Hano: Acid-hydrolysis of fish wastes for lactic acid fermentation. Bioresour.Technol., 97, 24142420 (2006).

Hartmann, R. and H. Meisel: Food-derived peptides with biological activity: from research to food applications. Curr. Opin. Biotechnol., 18, 163-169 (2007).

Heu, M.S. and J.S. Kim: Comparison of quality among boiled-dried anchovies caught from different sea. J. Korean Fish. Soc., 35, 173178(2002).

Hordur, G.K. and A.R. Barbara: Fish protein hydrolysates: Production, biochemical and functional properties. Crit. Rev. Food Sci. Nutr., 40, 43-81 (2000).

Hsu, K.C., G.H. Lu and C.L. Jao: Antioxidative properties of peptides prepared from tuna cooking juice hydrolysates with orientase (Bacillus subtilis). Food Res. Int., 42, 647-652 (2009).

Iwai, K., N. Kishimoto, Y. Kakino, K. Mochida and T. Fujita: In vitro antioxidative effects and tyrosinase inhibitory activities of seven hydroxycinnamoyl derivatives in green coffee beans. J. Agric. Food Chem., 52, 4893-4898 (2004).

Ji, C.I., J.H. Lee, D.C. Park, Y.S. Gu and I.S. Kim: Angiotensin converting enzyme inhibitory activity in peptic hydrolysates of cooking discards from anchovy factory ship. Korean J. Food Sci. Technol., 
34, 529-532 (2002).

Kruse, A. and E. Dinjus: Hot compressed water as reaction medium and reactant properties and synthesis reactions. J. Supercrit. Fluids, 39, 362-380 (2007).

Marklund, S. and G. Marklund: Involvement of superoxide aminoradical in the oxidation of pyrogallol and a convenient assay for superoxide dismutase. Eur. J. Biochem., 47, 468-474 (1975).

Ministry of Oceans and Fisheries. http://www.fips.go.kr/jsp/sf/ss/ss kind law list.jsp?menuDepth=070104, assessed at Dec. 14, 2013.

Oh, T.Y., J.I. Kim, Y.I. Seo and E.S. Cho: The population genetic structure of the Japanese Anchovy (Engraulis japonicas Temminck and Schlegel) in the West, South and East Seas of Korea based on microsatellite DNA analysis. J. Life Sci., 19, 174-178 (2009).

Oh, K.S., R.H. Ro, E.H. Lee and H.Y. Park: Processing of the intermediate product (frozen seasoned anchovy meat) derived from anchovy. Korean J. Food Sci. Technol., 21, 498-504 (1989).

Pádraigín, A.H. and J.F. Richard: Bioactive peptides from marine processing waste and shellfish: A review. J. Funct. Foods, 4, 6-24 (2012).

Park, J.H., Y.M. Kim, D.S. Kim and S.M. Kim: Functionality of low molecular weight peptides of acceleratedly manufactured anchovy sauce with Bacillus subtilis JM3 protease. Korean J. Food Sci.
Technol., 37, 827-832 (2005).

Re, R., N. Pellegrini, A. Proteggente, A. Pannala and M. Yang: RiceEvans C. Antioxidant activity applying an improved ABTS radical cation decolorization assay. Free Radic. Biol. Med., 26, 1231-1237 (1999).

Rogalinski, T., K. Liu, T. Albrecht and G. Brunner: Hydrolysis kinetics of biopolymers in subcritical water. J. Supercrit. Fluids, 46, 335-341 (2008).

Simopoulos, A.P.: Omega-3 fatty acids in health and disease and in growth and development. Am. J. Clin. Nutr., 54, 438-463 (1991).

Toor, S.S., L. Rosendahl and A. Rudolf: Hydrothermal liquefaction of biomass: A review of subcritical water technologies. Energy, 36, 2328-2342 (2011).

Uddin, M.S., H.M. Ahn, H. Kishimura and B.S. Chun: Production of valued materials from squid viscera by subcritical water hydrolysis. J. Environ. Biol., 31, 675-679 (2010).

Udenigwe, C.C. and R.E. Aluko: Food protein-derived bioactive peptides: production, processing, and potential health benefits. J. Food Sci., 71, 11-24 (2012).

Zhu, X., C. Zhu, L. Zhao and H. Cheng: Amino acids production from fish proteins hydrolysis insubcritical water. Chin. J. Chem. Eng., 16, 456-460 (2008). 